\title{
Highly Active and Stable Single-Atom Cu Catalysts Supported by a Metal-Organic Framework
}

\author{
Ali M. Abdel-Mageed, ${ }^{1, ~ \# ~ B u n y a r a t ~ R u n g t a w e e v o r a n i t, ~}{ }^{2,3}, \#$ Magdalena Parlinska-Wojtan, ${ }^{4}$ Xiaokun \\ Pei, ${ }^{2,3}$ Omar M. Yaghi, ${ }^{2,3, *}$ and R. Jürgen Behm, ${ }^{1 *}$ \\ ${ }^{1}$ Institute of Surface Chemistry and Catalysis, Ulm University, D-89069 Ulm, Germany \\ ${ }^{2}$ Department of Chemistry and Kavli Energy NanoSciences Institute, University of California—Berkeley, CA 94720, \\ $\mathrm{USA}^{3}$ \\ Materials Sciences Division, Lawrence Berkeley National Laboratory, CA 94720, USA \\ ${ }^{4}$ Institute of Nuclear Physics, Polish Academy of Sciences, Krakow 31-342, Poland
}

\begin{abstract}
Single-atom catalysts are often considered as the ultimate design principle for supported catalysts, due to their unique geometric and electronic properties, and their highly efficient use of precious materials. Here, we report a single-atom catalyst, $\mathrm{Cu} / \mathrm{UiO}-66$, prepared by a covalent attachment of $\mathrm{Cu}$ atoms to the defect sites at the zirconium oxide clusters of the metal-organic framework (MOF) UiO-66. Kinetic measurements showed this catalyst to be highly active and stable under realistic reaction conditions for two important test reactions, the oxidation of $\mathrm{CO}$ at temperatures up to $350^{\circ} \mathrm{C}$, which makes this interesting for application in catalytic converters for cars, and for $\mathrm{CO}$ removal via selective oxidation of $\mathrm{CO}$ in $\mathrm{H}_{2}$-rich feed gases, where it shows an excellent selectivity of about $100 \%$ for $\mathrm{CO}$ oxidation. Timeresolved operando spectroscopy measurements indicate that the activity of the catalyst is associated with atomically dispersed, positively charged ionic $\mathrm{Cu}$ species. Density functional theory (DFT) calculations in combination with experimental data show that $\mathrm{Cu}$ binds to the $\mathrm{MOF}$ by ${ }^{-} \mathrm{OH} / \mathrm{OH}_{2}$ ligands capping the defect sites at the $\mathrm{Zr}$ oxide clusters.
\end{abstract}

\section{INTRODUCTION}

Reduction of the size of metal nanoparticles in supported catalysts to the atomic limits, ultimately arriving at socalled single-atom catalysts, has been a long-standing dream in heterogeneous catalysis, both to maximize the fraction of active sites and increase their selectivity for specific reaction pathways. ${ }^{1-4}$ The challenge is, however, to stabilize and prevent the individual metal atoms or small clusters from migrating and sintering during reaction, which is a common cause of catalyst deactivation, especially at high temperatures. ${ }^{5-7}$ Extensive efforts to solve this problem have focused on loading minute amounts of active metal onto supports with high surface area such as activated carbon, zeolites or metal oxides. This approach depends largely on providing sufficiently large spacings between active metal species. However, precise control of the spatial location and the local environment of such metal atoms or small clusters on these mostly ill-defined surface structures remain difficult. We envisaged another approach, using a regularly structured metal-organic framework (MOF) as template, where active metal atoms are attached to specific sites. ${ }^{8-10}$ In addition to the welldefined environment of the active metal atoms, ${ }^{11-14}$ metalsupport interactions may assist also in stabilizing these atoms and thus hinder sintering. ${ }^{12 ; 15 ; 16}$ Although anchoring of metal atoms at metal oxide clusters in MOFs has been reported in a number of studies, these metal atoms sinter under reducing condition due to the presence of nearby metal atoms or the lack of interaction with MOFs. ${ }^{10 ; 7-19}$

In the present contribution, we report on a single atom $\mathrm{Cu} / \mathrm{UiO}-66$ catalyst, where $\mathrm{Cu}$ atoms are covalently attached to the defect sites of the $\mathrm{Zr}$ oxide clusters in UiO66, $\mathrm{Zr}_{6} \mathrm{O}_{4}(\mathrm{OH})_{4}(\mathrm{BDC})_{5}\left(\mathrm{CH}_{3} \mathrm{COO}\right)_{0.7}\left(\mathrm{H}_{2} \mathrm{O}\right)_{1.3}(\mathrm{OH})_{1.3}\left(\mathrm{BDC}^{2-}\right.$ $=1,4$-benzenedicarboxylate), and the performance of these catalysts in the $\mathrm{CO}$ oxidation reaction under completely realistic reaction conditions. This reaction is a key reaction in heterogeneous catalysis, both from a fundamental point of view and for practical applications, e.g., for reducing $\mathrm{CO}$ emissions in exhaust gases or for the removal of $\mathrm{CO}$ from $\mathrm{H}_{2}$-rich feed gases for ammonia synthesis and low temperature fuel cell applications. ${ }^{20} \mathrm{We}$ used a combination of kinetic as well as time-resolved operando and ex situ spectroscopy and electron microscopy measurements, and of computational studies, which provided detailed insight into the structure and electronic properties of the catalyst during activation and subsequent reaction, making use also of the well-defined structure of the catalyst. 


\section{EXPERIMENTAL METHODS}

Synthesis of the catalyst $\mathrm{UiO}-66 .{ }^{15}$ In a $20 \mathrm{~mL}$ scintillation vial, 1,4-benzenedicarboxylic acid and zirconium tetrachloride were dissolved in a solution containing DMF (10 $\mathrm{mL}$ ) and acetic acid ( $0.7 \mathrm{~mL})$. The vial was sealed and heated isothermally at $120{ }^{\circ} \mathrm{C}$ for a day. Subsequently, UiO-66 powder was collected by centrifugation, washed and dried under dynamic vacuum overnight (further details in the Supporting Information, Section $\mathrm{S}_{1}$ ).

$\mathrm{Cu} / \mathrm{UiO}-66$. UiO-66 (6oo $\mathrm{mg}$ ) was added to the solution containing $\mathrm{CuCl}_{2} \cdot 2 \mathrm{H}_{2} \mathrm{O}$ (Aldrich, 99.99\%, $540 \mathrm{mg}$ ) dissolved in DMF (9 mL). The suspension was sonicated for one minute. The vial's thread was wrapped with PTFE tape and the vial was sealed and heated in an $85{ }^{\circ} \mathrm{C}$ isothermal oven for a day. Finally, the product was collected by centrifugation, washed and dried under dynamic vacuum overnight (further details in the Supporting Information, Section $\mathrm{S}_{1}$ ).

Activity measurements. The kinetic measurements were carried out after pretreatment $\left(10 \% \mathrm{H}_{2} / \mathrm{N}_{2}\right.$ for $1 \mathrm{~h}$ at 250 ${ }^{\circ} \mathrm{C}$ ) in a quartz tube microreactor (4 $\mathrm{mm}$ inner diameter) at atmospheric pressure, where the as-received catalyst powder was positioned in the middle of the reactor and fixed on both sides by a piece of quartz wool. All measurements were carried out using high purity gases (99.999\%, supplied by Westfalen AG) and Hastings HFC202 mass flow controllers for preparing gas mixtures. Activity measurements were performed in idealized $(1 \%$ $\mathrm{CO}, 1 \% \mathrm{O}_{2}, \mathrm{~N}_{2}$ balance), $\mathrm{O}_{2}$-rich ( $1 \% \mathrm{CO}, 21 \% \mathrm{O}_{2}, \mathrm{~N}_{2}$ balance) and $\mathrm{H}_{2}$-rich $\left(1 \% \mathrm{CO}, 1 \% \mathrm{O}_{2}, 80 \% \mathrm{H}_{2}, \mathrm{~N}_{2}\right.$ balance) gas mixtures. Evaluation of the Weisz criterion showed the absence of mass-transport related problems. ${ }^{21}$ Influent and effluent gases were analyzed by online gas chromatography (GC) with a $\mathrm{CO}$ detection limit of $<10 \mathrm{ppm}$ (DANI 86.10), using $\mathrm{H}_{2}$ as a carrier gas. The GC was equipped with two columns packed with Hayesep $\mathrm{Q}$ polymer for separating $\mathrm{CO}, \mathrm{O}_{2}$, and $\mathrm{N}_{2}$ and molecular sieve (5 $\AA$ ) for separating $\mathrm{CO}_{2}$ and $\mathrm{H}_{2} \mathrm{O}$. For gas composition analysis, two thermal conductivity detectors (TCDs) were used. The $\mathrm{Cu}$ mass-normalized reaction rates $\left(R_{\mathrm{CO}}\right)$ were calculated from the $\mathrm{CO}$ conversion $\left(\mathrm{X}_{\mathrm{CO}}\right)$ under differential reaction conditions $\left(X_{\mathrm{CO}}<\mathbf{2 0} \%\right)$ in the idealized reaction gas, using the molar flow rate of $\mathrm{CO}$ into the reactor $\left(\mathrm{n}_{\mathrm{CO}, \mathrm{in}}\right)$, and the absolute mass of $\mathrm{Cu}$ metal in the catalyst $\left(\mathrm{m}_{\mathrm{Cu}}\right)$ according to eq. (1). Differential reaction conditions were ensured by diluting the catalyst with $\alpha-\mathrm{Al}_{2} \mathrm{O}_{3}$, which is catalytically inactive under these conditions (pure catalyst: 10 - $120 \mathrm{mg}$ ). The selectivity for $\mathrm{CO}$ oxidation $(S)$ during PROX measurements was obtained from the formation of $\mathrm{CO}_{2}\left(X_{\mathrm{CO}_{2}}\right)$ and water $\left(X_{\mathrm{H}_{2} \mathrm{O}}\right)$, according to eq. (2) Including the atomic mass of $\mathrm{Cu}\left(\mathrm{M}_{\mathrm{Cu}}\right)$ and metal dispersion $\left(\mathrm{D}_{\mathrm{Cu}}=100 \%\right.$ considering atomic dispersion) TOF values were obtained according to eq. 3 .

$$
\begin{aligned}
& R_{C O}=\frac{\dot{X}_{C O} \dot{n}_{C O, i n}}{m_{C u}} \\
& S=\frac{X_{C O 2}}{X_{C O}+X_{H 2 O}} \times 100 \\
& T O F_{C O}=\frac{R_{C O} \times M_{C u}}{D_{C u}}
\end{aligned}
$$

Operando DRIFTS measurements. Time-resolved operando DRIFTS measurements were carried out using a commercial reaction cell (Harricks, HV-DR2), in a continuous flow of reaction gases, with the gases flowing through the catalyst bed from top to bottom, similar to the set-up used in kinetic measurements. Measurements were performed under differential reaction conditions, following a $\mathrm{H}_{2}$ pretreatment. The effluent reaction gases were continuously monitored by transmission infrared spectrometry, using an FTIR spectrometer (Alpha Bruker Optics Inc.) coupled with a substrate-integrated hollow waveguide (iHWG). ${ }^{22}$ The DRIFTS spectra were recorded using a Magna 6700 spectrometer (Thermo-Fischer), equipped with an MCT narrow-band gap detector. ${ }^{23}$ The intensities of different bands were evaluated in KubelkaMunk units (KMU), which are linearly proportional to the coverage of adsorbed surface species. ${ }^{24}$ Background subtraction and normalization of the spectra were performed using spectra recorded in a flow of $\mathrm{N}_{2}$ directly after the catalyst pretreatment, normalizing to identical intensity at $3855 \mathrm{~cm}^{-1}$. For comparison of $\mathrm{UiO}-66$ and $\mathrm{Cu} / \mathrm{UiO}-66$, the spectra were normalized at the $\mu-\mathrm{OH}$ vibration of the $\mathrm{Zr}$ secondary building unit located at $3666 \mathrm{~cm}^{-1}$.

Operando XAS measurements. Operando XANES and EXAFS measurements were conducted in transmission mode at the $\mathrm{Cu}$ K-edge at the $\mathrm{P}_{5}$ beamline of the Petra-3 extension (DESY) and at the XAFS beamline of the Elettra Synchrotrone. In all experiments, we used a specially designed reaction cell, which was described in detail elsewhere. ${ }^{25}$ The measurements were carried out under differential reaction conditions ( $\mathrm{CO}$ conversion $<5 \%$ ) after identical pretreatment to that described in kinetic measurements using $\sim 20 \mathrm{mg}$ of diluted $\mathrm{Cu} / \mathrm{UiO}-66$ under a continuous flow of idealized $\mathrm{CO}$ oxidation gas mixture, where the conversion was recorded using on-line gas chromatography (influent and effluent gases). Although the much higher space velocity in the XAS measurements led to different reaction rates compared to the kinetic measurements in the microreactor, the trend of catalyst activation agrees well with the respective microreactor data (Supporting Information, Figure S13).Background subtraction and normalization of the XANES spectra were performed using the Athena software from the IFEFFIT program package. ${ }^{26}$ Linear combination fitting of the XANES spectra was carried out using reference spectra of $\mathrm{Cu}$ foil, $\mathrm{CuO}$ and $\mathrm{Cu}_{2} \mathrm{O}$. For data reduction and evaluation of the EXAFS spectra we used the XDAP software package with standard procedures described elsewhere. ${ }^{27 ; 28}$ Theoretical references were calculated by the FEFF 8.o code and then calibrated using experimental EXAFS spectra of $\mathrm{Cu}$ foil and $\mathrm{CuO}$ as well as $\mathrm{Cu}_{2} \mathrm{O}$ powder as experimental references. $^{27 ; 29}$ EXAFS data were evaluated in R-space using fixed $\mathrm{k}$ and $\mathrm{R}$ ranges (k: 2.8-9.5 $\AA^{-1}$; R: 0.0-5.0 $\AA$ ). The data were fitted to the shortest back-scatterer distance around the $\mathrm{Cu}$ absorber (i.e., first $\mathrm{Cu}-\mathrm{Cu}, \mathrm{Cu}-\mathrm{Zr}$ and $\mathrm{Cu}-\mathrm{O}$ shell); the bond length, coordination number $(\mathrm{CN})$, internal energy shift $\left(\mathrm{E}_{\mathrm{o}}\right)$, and Debye-Waller factor (DWF) were allowed to change freely (resulting values ranged from 0.003 to $0.004 \AA^{2}$ ). 
Electron microscopy. High-angle annular dark-field scanning transmission electron microscopy (HAADFSTEM) measurements were performed on a Cs-corrected FEI Titan electron microscope operated at $300 \mathrm{keV}$. Energy dispersive spectroscopy (EDS) mapping was carried out on a Talos F20o FEI TEM microscope operated at 200 $\mathrm{keV}$, which is equipped with a FEG cathode and the Super EDS system. The sample was dispersed in ethanol and dip-coated on a carbon coated Ni grid.

X-ray photoelectron spectroscopy (XPS). XPS measurements were carried out on a PHI 5800 ESCA system (Physical Electronics) using monochromatic $\mathrm{Al}-\mathrm{K}_{\alpha}$ radiation $(1486 \mathrm{eV})$ and an electron emission angle of $45^{\circ}$. Pass energies were $93.9 \mathrm{eV}$ for survey spectra and $29.35 \mathrm{eV}$ for high-resolution spectra. XPSPEAK41 software was used to deconvolute the measured signals, employing a Shirley

a)

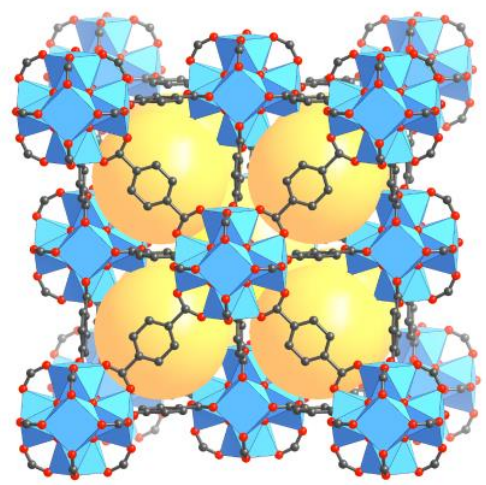

Defect-free UiO-66

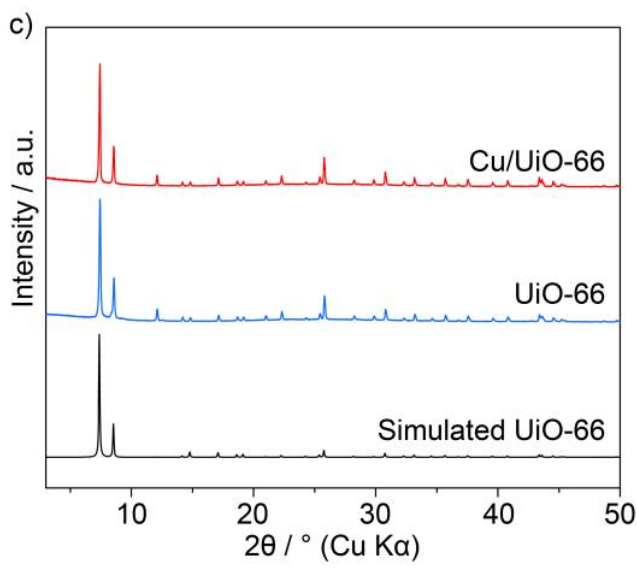

background correction and Gaussian/Lorentzian peak shapes. The binding energies (BEs) of all spectra were calibrated by $\mathrm{C}(\mathrm{ss})$ peak of ubiquitous carbon at $284.8 \mathrm{eV}$.

\section{RESULTS AND DISCUSSION}

Synthesis of $\mathrm{Cu} / \mathrm{UiO}-66$ catalyst. We synthesized UiO-66 using acetic acid as a modulator to control the particle size and obtain highly crystalline MOF (Figure 1a). As commonly observed, the MOF prepared here contains missing linkers, resulting in defect sites on the $\mathrm{Zr}$ oxide cluster. $^{30-33}$ From $1 \mathrm{H}$ nuclear magnetic resonance (NMR) analysis, elemental analysis and thermal gravimetric analysis (Supporting Information, Figures $\mathrm{S}_{1}-\mathrm{S}_{3}$ ), we found that the MOF contains about one missing linker per one $\mathrm{Zr}_{6}$ cluster and that the resulting defect

b)

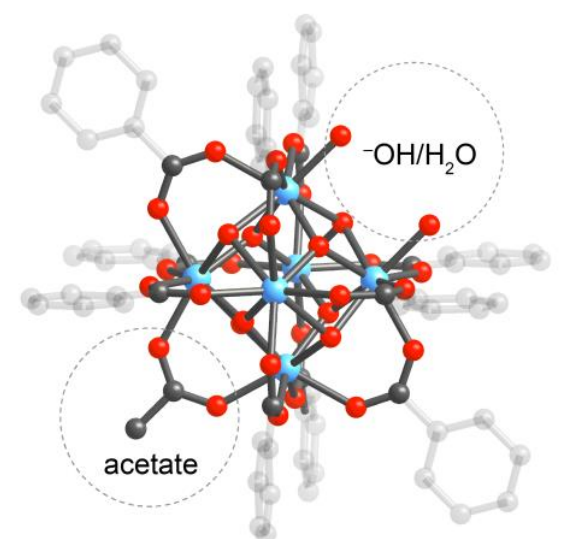

Cluster of UiO-66 with missing linker defects

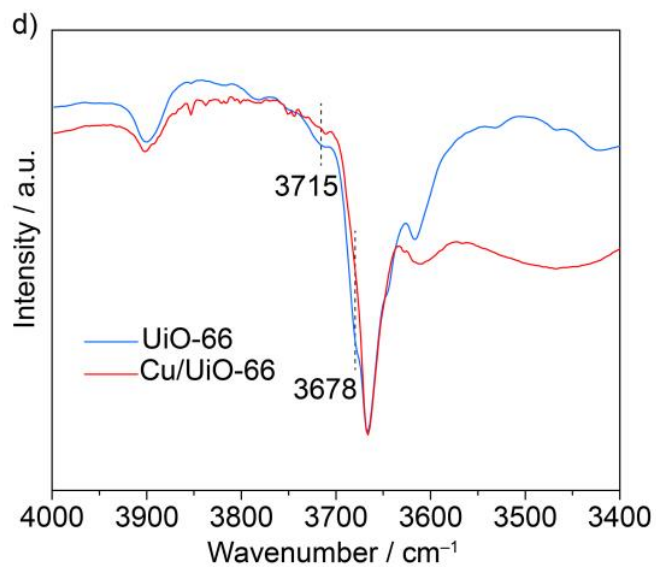

Figure 1. (a) Crystal structure of defect-free UiO-66 (yellow spheres represent the space in the framework). (b) $\mathrm{Zr}$ oxide cluster of $\mathrm{UiO}-66$ with ${ }^{-} \mathrm{OH} / \mathrm{OH}_{2}$ and acetate molecules replacing terephthalate linkers. Atom labeling scheme: $\mathrm{C}$ : black; O: red; $\mathrm{Zr}$ : blue ( $\mathrm{H}$ atoms are omitted for clarity). (c) Measured PXRD diffractograms of UiO-66 and $\mathrm{Cu} / \mathrm{UiO}-66$ in comparison with a simulated diffractogram of UiO-66. (d) DRIFTS spectrum of UiO-66 overlaid with that of Cu/UiO-66.

sites are terminated by acetate and ${ }^{-} \mathrm{OH} / \mathrm{OH}_{2}$ groups. This yields $\mathrm{Zr}_{6} \mathrm{O}_{4}(\mathrm{OH})_{4}\left(\mathrm{C}_{8} \mathrm{H}_{4} \mathrm{O}_{4}\right)_{5}\left(\mathrm{CH}_{3} \mathrm{COO}\right)_{0.7}\left(\mathrm{H}_{2} \mathrm{O}\right)_{1.3}(\mathrm{OH})_{1.3}$ as the actual chemical composition of the UiO-66 material synthesized here (Figure $1 \mathrm{~b}$ ). $\mathrm{Cu} / \mathrm{UiO}-66$ catalyst was prepared by heating $\mathrm{UiO}-66$ in a solution of $\mathrm{CuCl}_{2} \cdot 2 \mathrm{H}_{2} \mathrm{O}$ in DMF at $85^{\circ} \mathrm{C}$ overnight to anchor $\mathrm{Cu}$ atoms at the oxygen atoms of ${ }^{-} \mathrm{OH} / \mathrm{OH}_{2}$ groups terminating the defect sites. Inductively coupled plasma optical emission spectroscopy (ICP-OES) analysis of $\mathrm{Cu} / \mathrm{UiO}-66$ shows the incorporation of $\mathrm{Cu}$ in $\mathrm{Cu} / \mathrm{UiO}-66$ with a $\mathrm{Cu}: \mathrm{Zr}_{6}$ atomic ratio of o.8. Independent of the excess of $\mathrm{CuCl}_{2} \cdot 2 \mathrm{H}_{2} \mathrm{O}$ used in the synthesis, this ratio remained constant, indicating that the defect sites of the UiO-66 are the limiting feature. Scanning electron microscopy (SEM) images of 
the materials before and after the loading of $\mathrm{Cu}$ show the typical octahedral morphology of UiO-66 crystals without any impurity phase (Supporting Information, Figure $\mathrm{S}_{4}$ ). Energy dispersive X-ray spectroscopic (EDS) analysis indicates the presence of $\mathrm{Cl}$, with a molar ratio of $\mathrm{Cu}: \mathrm{Cl}$ of about 1, suggesting that $\mathrm{Cl}^{-}$may function as a ligand coordinating to $\mathrm{Cu}$ (Supporting Information, Figure $\mathrm{S}_{5}$ ). From transmission electron microscopy (TEM) images of the fresh $\mathrm{Cu} / \mathrm{UiO}-66$ (Supporting Information, Figure S6a), we did not find any evidence for $\mathrm{Cu}$ or $\mathrm{CuO}_{x}$ nanoparticle formation. Powder X-ray diffraction (PXRD) of $\mathrm{Cu} / \mathrm{UiO}$ 66 displays the reflections expected from simulation of UiO-66, supporting the phase purity of UiO-66 (Figure 1c). Diffuse reflectance FTIR spectroscopy (DRIFTS) spectra of $\mathrm{Cu} / \mathrm{UiO}-66$ obtained under a continuous flow of $\mathrm{N}_{2}$ at $250^{\circ} \mathrm{C}$ show a significantly lower intensity of the bands at 3715 and $3678 \mathrm{~cm}^{-1}$ compared to that observed for UiO66 , which are attributed to the $\mathrm{O}-\mathrm{H}$ stretch vibrations of the defect sites on the $\mathrm{Zr}$ oxide clusters (Figure $1 \mathrm{~d}$ ). This can be explained by a mechanism, where $\mathrm{Cu}$ atoms are coordinating to ${ }^{-} \mathrm{OH} / \mathrm{OH}_{2}$ species on $\mathrm{UiO}-66$.

To gain more information on the structure of the catalyst, we prepared a single crystal of $\mathrm{Cu} / \mathrm{UiO}-66$, following a similar metalation procedure as used for microcrystalline $\mathrm{Cu} / \mathrm{UiO}-66$ sample. Single crystal X-ray diffraction (SCXRD) analysis reveals that $\mathrm{Cu} / \mathrm{UiO}-66$ crystallizes in the $F m-3 m$ space group with a structure similar to the native UiO-66 (Supporting Information, Section S2.5; Figure $\mathrm{S}_{7}$ and Figure S8), indicating that the framework remains unperturbed upon $\mathrm{Cu}$ metalation. However, the disorder and the low concentration of the dispersed $\mathrm{Cu}$ atoms did not allow for an unambiguous identification of the $\mathrm{Cu}$ configuration by SCXRD (see Supporting Information, section $\mathrm{S}_{2.5}$ ).

Therefore, we performed operando X-ray absorption spectroscopy (XAS) measurements of the $\mathrm{Cu} / \mathrm{UiO}-66$ catalyst to obtain further information on the structure of the $\mathrm{Cu}$ site, which will be discussed further below.

CO oxidation and preferential CO oxidation. Before reaction, we pretreated $\mathrm{Cu} / \mathrm{UiO}-66$ catalyst in $10 \% \mathrm{H}_{2} / \mathrm{N}_{2}$ at $250{ }^{\circ} \mathrm{C}$ for $1 \mathrm{~h}$. Subsequently, the catalytic activity for $\mathrm{CO}$ oxidation was measured in an idealized gas mixture ( $1 \% \mathrm{CO}$, $1 \% \mathrm{O}_{2}, \mathrm{~N}_{2}$ balance) at $250{ }^{\circ} \mathrm{C}$ for almost $37.5 \mathrm{~h}$ (Figure 2a). The catalyst first passed through a pronounced activation phase, which lasted over $\mathbf{1 2 . 5} \mathrm{h}$, followed by a slowly increasing activity, until it reached its highest activity at about $57 \%$ conversion after $\sim 25 \mathrm{~h}$ on stream. Afterwards the activity decayed slightly, losing about $2 \%$ conversion up to $37.5 \mathrm{~h}$ on stream. We also examined the temperature-dependence of the catalytic activity between $80^{\circ} \mathrm{C}$ and $250^{\circ} \mathrm{C}$ under differ- ential reaction conditions, using appropriate amounts of catalyst at each temperature. As depicted in Figure $2 \mathrm{~b}$, the $\mathrm{Cu}$ mass normalized activity and the corresponding turnover frequencies (TOFs) display an essentially exponential dependence on the reaction temperature, which reflects an apparent activation energy of $43.5 \pm 2 \mathrm{~kJ} \mathrm{~mol}^{-1}$. Assuming that all $\mathrm{Cu}$ atoms are accessible to the reactants, TOF values were determined to be between $0.22 \times 10^{-3} \mathrm{~s}^{-1}$ at $80{ }^{\circ} \mathrm{C}$ and $17.5 \times$ $10^{-3} \mathrm{~s}^{-1}$ at $250^{\circ} \mathrm{C}$ (Figure 2d). Considering a possible application in catalytic converters in cars, where $350^{\circ} \mathrm{C}$ is a typical reaction temperature under high load conditions, ${ }^{34}$ we tested the catalyst performance at $350^{\circ} \mathrm{C}$ under otherwise identical conditions. Over more than $20 \mathrm{~h}$ we did not find any measurable decay in reaction rate (Supporting Information, Figure S9).

Finally, we evaluated the influence of excess oxygen on the catalyst performance under these conditions, reacting $1 \% \mathrm{CO}$ in synthetic air $\left(21 \% \mathrm{O}_{2}, 78 \% \mathrm{~N}_{2}\right)$ at $350^{\circ} \mathrm{C}$ (Figure 2c). Under these conditions, the catalyst shows a CO conversion of $98 \%$ for over $700 \mathrm{~min}$. Upon reducing the temperature to $250^{\circ} \mathrm{C}$, the CO conversion decayed to $\sim 65 \%$. To further test the response of the catalyst to dynamic variations of the load, in this case to complete shutdown of the engine, we removed $\mathrm{CO}$ from the gas feed and abruptly decreased the temperature to $25^{\circ} \mathrm{C}$ under a continuous flow of synthetic air for $2 \mathrm{~h}$. Afterward, the original feed gas was reconnected, and the temperature was increased to $250{ }^{\circ} \mathrm{C}$ within $5 \mathrm{~min}$. After a short period of time, where an overshoot in temperature caused a slightly higher $\mathrm{CO}$ conversion, we arrived at essentially the same $\mathrm{CO}$ conversion as before the shutdown procedure. Further increasing the reaction temperature to $350{ }^{\circ} \mathrm{C}$ also led to about the same conversion of $98 \%$, identical to the original value before the shutdown step. Hence, the shutdown procedure did not cause any measurable irreversible loss in activity. Comparing the $\mathrm{CO}$ oxidation activity of $\mathrm{Cu} / \mathrm{UiO}-66$ under these conditions to that of $\mathrm{Cu} / \mathrm{CeO}_{2}$ and $\mathrm{Cu} / \mathrm{ZrO}_{2}$, which are among the most active $\mathrm{Cu}$-based catalysts for $\mathrm{CO}$ oxidation, $\mathrm{Cu} / \mathrm{UiO}-66$ catalyst is at least 3 times more active based on the $\mathrm{CO}$ conversion for similar $\mathrm{Cu}$ masses. ${ }^{35: 36}$ Compared to $\mathrm{Pt} / \mathrm{CeO}_{2}$ catalysts, for the same metal loading, the activity is in the same order of magnitude at temperatures around $200{ }^{\circ} \mathrm{C} .{ }^{37}$

As a second example, we evaluated the catalyst performance for the preferential oxidation of CO (PROX) in a $\mathrm{H}_{2}$-rich reformate gas $\left(1 \% \mathrm{CO}, 1 \% \mathrm{O}_{2}, 18 \% \mathrm{~N}_{2}\right.$ and $\left.80 \% \mathrm{H}_{2}\right)$ (Figure $2 \mathrm{~d}$ ), where $\mathrm{CO}$ should be completely removed, while the competing oxidation of $\mathrm{H}_{2}$ should be kept as low as possible. At $120^{\circ} \mathrm{C}$, the catalyst showed no measurable activity for $\mathrm{H}_{2}$ oxidation (Supporting Information, Figure S1o), while the $\mathrm{CO}$ oxidation activity is around 2.3 $\mu \mathrm{mol} \mathrm{g}_{\mathrm{Cu}}{ }^{-1} \mathrm{~s}^{-1}$, which is slightly lower than 

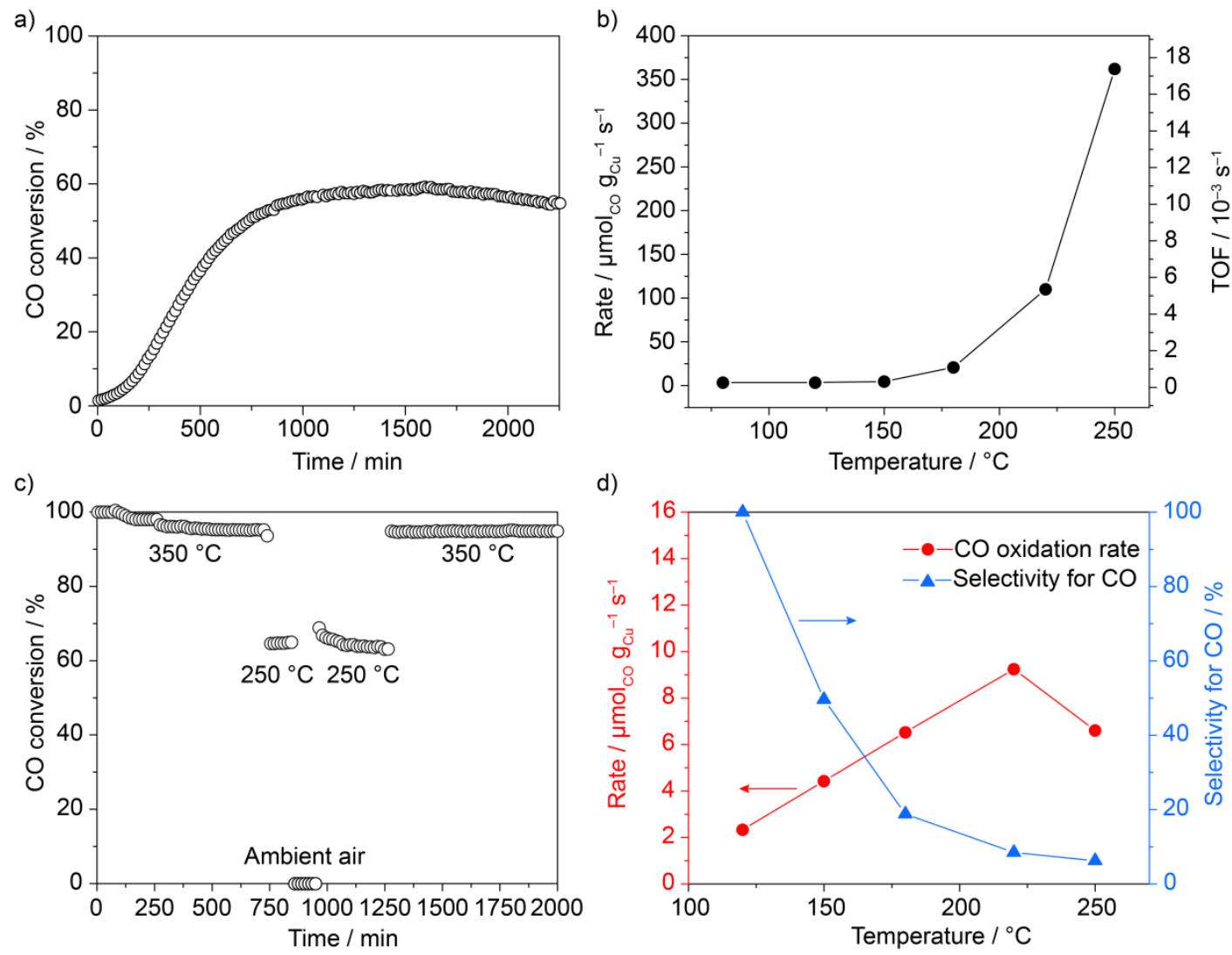

Figure 2. (a) $\mathrm{CO}$ oxidation during time on stream based on the $\mathrm{CO}$ conversion signal at $250^{\circ} \mathrm{C}$ on 120 mg of the catalyst (1:4 dilution) after pretreatment $\left(10 \% \mathrm{H}_{2} / \mathrm{N}_{2}\right.$ for $1 \mathrm{~h}$ at $\left.250{ }^{\circ} \mathrm{C}\right)$ in an idealized reaction gas mixture $\left(1 \% \mathrm{CO}, 1 \% \mathrm{O}_{2}, \mathrm{~N}_{2}\right.$ balance -30 $\mathrm{NmL} \mathrm{min}^{-1}$ ). (b) Temperature dependence of the reaction rates and turnover frequencies (TOFs) between 80 and $250{ }^{\circ} \mathrm{C}$ after reaching steady state at $250^{\circ} \mathrm{C}$ in idealized reaction gas mixture. (c) CO conversion in synthetic air $\left(1 \% \mathrm{CO}_{2}, 21 \% \mathrm{O}_{2}\right.$, balance $\mathrm{N}_{2}-$

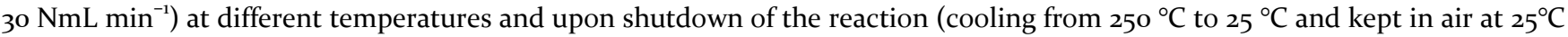
for $2 \mathrm{~h}$ ) and restart by heating in reaction gas mixture to $250^{\circ} \mathrm{C}$ and subsequently to $350{ }^{\circ} \mathrm{C}$. (d) $\mathrm{Cu}$ mass normalized $\mathrm{CO}$ oxidation rates at different temperatures $\left(120-250{ }^{\circ} \mathrm{C}\right)$ as determined in a measurement at different temperatures in a $\mathrm{H}_{2}$-rich preferential $\mathrm{CO}$ oxidation gas mixture $\left(1 \% \mathrm{CO}, 1 \% \mathrm{O}_{2}, 80 \% \mathrm{H}_{2}, \mathrm{~N}_{2}\right.$ balance $\left.-30 \mathrm{NmL} \mathrm{min}^{-1}\right)$ and catalyst selectivity for CO oxidation (see details in section 'Methods').

in the absence of $\mathrm{H}_{2}\left(3.5 \mu \mathrm{mol} \mathrm{g}_{\mathrm{Cu}}{ }^{-1} \mathrm{~s}^{-1}\right)$ under otherwise identical reaction conditions. This is different from the behavior of supported $\mathrm{Au}$ and $\mathrm{Pt}$ catalysts, where the presence of $\mathrm{H}_{2}$ tended to increase the $\mathrm{CO}$ oxidation rate. ${ }^{38 ; 39}$ This results in a selectivity for $\mathrm{CO}$ oxidation of about $100 \%$. In contrast to the $\mathrm{CO}$ oxidation in $\mathrm{H}_{2}$-free reaction gas (Figure $2 \mathrm{~b}$ ), the $\mathrm{CO}$ oxidation rate increased about linearly with increasing temperature in the $\mathrm{H}_{2}$-rich gas mixture up to $220^{\circ} \mathrm{C}$. (Figure $2 \mathrm{~d}$ ), and then decayed onward to $250{ }^{\circ} \mathrm{C}$. The selectivity for $\mathrm{CO}$ oxidation, on the other hand, decreased with increasing temperature. Considering the constant $\mathrm{H}_{2}$ conversion between 220 and $250{ }^{\circ} \mathrm{C}$ (Supporting Information, Figure S1o), the decay in $\mathrm{CO}$ rate at $250{ }^{\circ} \mathrm{C}$ most likely results from the increasing competition for $\mathrm{O}_{2}$ due to the high $\mathrm{H}_{2}$ oxidation rate. This conclusion of about $100 \%$ selectivity was confirmed by an additional measurement at higher $\mathrm{CO}$ conversion (ca. $5 \%$ ), which also revealed a selectivity toward CO oxidation of about $100 \%$ (error $\pm 1.5 \%$ ) over 950 min (Supporting Information, Figure $\mathrm{S} 10)$.

After the reaction, we examined the structural integrity of the catalyst using a combination of PXRD, TEM and DRIFTS measurements. The comparison of the PXRD patterns of the fresh and the spent $\mathrm{Cu} / \mathrm{UiO}-66$ catalysts (Figure 1 and Supporting Information, Figure S11), after the exposure to the reaction as described with Figure $2 \mathrm{c}$, indicates that the phase purity and crystallinity of the catalyst are retained, underlining the high stability of the catalyst. Furthermore, bright field TEM images show no significant changes in the shape and size distribution of the MOF crystals after $\mathrm{CO}$ oxidation, based on an evaluation of over 600 crystals. In both cases neither $\mathrm{Cu}$ nor $\mathrm{Cu}$ oxide clusters could be detected (Supporting Information, Figure S6). The stability of the organic component of the catalyst was investigated by DRIFTS measurements. Measurements performed after different activation and reaction steps showed no measurable differences in the IR spectra, further supporting the high stability of the $\mathrm{Cu} / \mathrm{UiO}-66$ catalyst during the reaction (Supporting Information, Figure $\mathrm{S}_{12}$ ).

Adsorption of $\mathrm{CO}$ during the reaction. Time-resolved operando DRIFTS measurements were performed during $\mathrm{CO}$ oxidation at $250{ }^{\circ} \mathrm{C}$ under a continuous flow of the idealized reaction gas mixture. Sequences of DRIFTS 
spectra are shown in Figure 3. The upper panel covers the initial phase of the reaction, ranging from o to $30 \mathrm{~min}$, and the lower one provides long-term information ex tending from $30 \mathrm{~min}$ to $1550 \mathrm{~min}$. Both panels show the

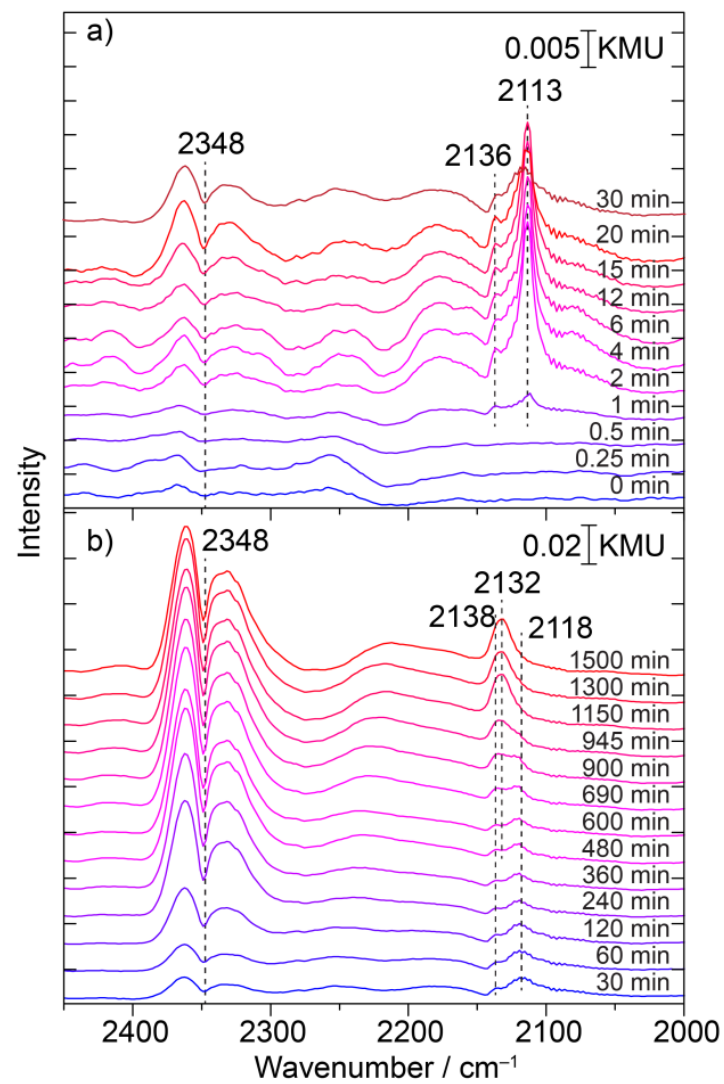

Figure 3. Selected DRIFTS spectra of $\mathrm{CO}$ adsorption and $\mathrm{CO}_{2}$ formation recorded during the first $20 \mathrm{~min}$ (a) and at extended reaction times from 30 to 1500 min (b) during $\mathrm{CO}$ oxidation in idealized $\mathrm{CO}$ oxidation gas mixture ( $1 \% \mathrm{CO}, 1 \% \mathrm{O}_{2}, \mathrm{~N}_{2}$ balance $-30 \mathrm{Nml} \mathrm{min}^{-1}, \mathrm{~T}=250^{\circ} \mathrm{C}$ ).

evolution of the $\mathrm{CO}_{2}$ gas phase signal with bands at 2332 and $2362 \mathrm{~cm}^{-1}$, whose intensity follows the trend of the $\mathrm{CO}$ oxidation rate with time (see the Supporting Information, Figure Siza for integrated intensity). During the initial 20 min, we found a distinct $\mathrm{CO}$ adsorption band at $2113 \mathrm{~cm}^{-1}$, which is near the position of $\mathrm{CO}$ adsorbed on oxidized $\mathrm{Cu}$ nanoparticles $\left(\mathrm{Cu}^{1+}\right.$-monocarbonyl species) at around $2130 \mathrm{~cm}^{-1}$ (Figure 3a), ${ }^{40 ; 41}$ suggesting the different environment of the covalently bound $\mathrm{Cu}$ species in the present case. This band starts to decrease in intensity after $20 \mathrm{~min}$ and decays to about $30 \%$ of its maximum intensity after $30 \mathrm{~min}$ in total. The same band is accompanied by a smaller shoulder at $2138 \mathrm{~cm}^{-1}$, which remains, however, rather weak and does not grow with time (Figure $3 \mathrm{~b}$ ). For longer reaction times, starting at about 600 min, a broader band centered around $2132 \mathrm{~cm}^{-1}$ developed and grew, which is characteristic for a $\mathrm{Cu}^{1+}$-monocarbonyl species. ${ }^{40 ; 41}$ This band remains stable for reaction times over 1200 min (Supporting Information, Figure S13b). In these assignments it has to be considered, however, that the wavenumber regions reported for $\mathrm{Cu}^{1+}$ mono- and multicarbonyls varied widely in previous studies. ${ }^{42}$ On the other hand, $\mathrm{Cu}^{2+}-\mathrm{CO}$ species were generally considered to be weakly bound and observed only at below ambient temperature. ${ }^{42}$ Altogether, these results indicate that there are significant changes in the adlayer and presumably also in the catalyst structure and electronic properties of the $\mathrm{Cu}$ species, once at $\mathrm{o}$ min and $\sim 20$ min on stream and once again after $600 \mathrm{~min}$ on stream. The former is most likely associated with an initial activation, which will be discussed in more detail after presenting the operando XAS data.

Geometric and electronic properties of the $\mathrm{Cu}$ site during the reactions. To further identify possible changes in the electronic properties and in the local coordination environment of the $\mathrm{Cu}$ species during the $\mathrm{CO}$ oxidation reaction, we performed time-resolved operando XAS measurements at the $\mathrm{Cu}$ K-edge (Figure 4) under a continuous flow of reaction gas (Supporting Information, Figure $\mathrm{S}_{14}$ ). In the near-edge region (Figure $4 \mathrm{~b}$ ), X-ray absorption near edge structure (XANES) spectra show a significant reduction of the white line intensity located at $\sim 8982 \mathrm{eV}$ after the hydrogen pretreatment of $\mathrm{Cu} / \mathrm{UiO}-66$ at $250{ }^{\circ} \mathrm{C}$, pointing to a reduction of the initial $\mathrm{Cu}^{2+}$ species. Comparison with the reference XANES spectra of $\mathrm{Cu}$, $\mathrm{Cu}_{2} \mathrm{O}$ and $\mathrm{CuO}$ (Figure 4a) ${ }^{43-45}$ shows that this corresponds to a change in the oxidation state of the majority of $\mathrm{Cu}$ species from $\mathrm{Cu}^{2+}$ to $\mathrm{Cu}^{1+}$, although there are still differences in details between spectra of the reduced $\mathrm{Cu} / \mathrm{UiO}-66$ catalyst and $\mathrm{Cu}_{2} \mathrm{O}$, e.g., in the onset behavior or in the exact position of the white line (see dashed line in Figure $4 \mathrm{~b}$ and Figure $\mathrm{S}_{15}$ in the Supporting Information). These differences, which are well outside the error range, point to distinct differences in the chemical environment of the $\mathrm{Cu}+1$ in the reduced $\mathrm{Cu} / \mathrm{UiO}-66$ catalyst and in the $\mathrm{Cu}_{2} \mathrm{O}$ reference. This will be discussed further with the EXAFS data presented below. In contrast to $\mathrm{Cu}$ species supported on NU-10oo, a Zr-based MOF, where $\mathrm{Cu}^{2+}$ were readily reduced and sintered to $\mathrm{Cu}^{\circ}$ under similar reduction conditions, $\mathrm{Cu}^{2+}$ species in $\mathrm{Cu} / \mathrm{UiO}-$ 66 are resistant towards complete reduction to $\mathrm{Cu}^{\circ}$, signifying the stability of this single-site catalyst, likely imposed by the presence of a single $\mathrm{Cu}$ atom per $\mathrm{Zr}$ cluster. For quantitative information we performed linear combination analysis (LCA) of the XANES spectra in Figure 4d. This confirms that an oxidation state of $1+$ is obtained for all $\mathrm{Cu}$ species after the $\mathrm{H}_{2}$ pretreatment. After changing to the reaction gas mixture, $55-60 \%$ of the initial $\mathrm{Cu}^{1+}$ species in the $\mathrm{Cu} / \mathrm{UiO}-66$ catalyst were re-oxidized to $\mathrm{Cu}^{2+}$ within $3 \mathrm{~min}$ on stream (Figure $4 \mathrm{c}$ ), e.g., to local $\mathrm{HO}-\mathrm{Cu}-$ $\mathrm{OH}$ coordinations. With increasing time, these species are converted to a $\mathrm{O}-\mathrm{Cu}-\mathrm{O}$ like coordination, as indicated by the shift of the edge jump to higher energy from the initial spectra to later ones (Figure $3 c$ ). ${ }^{46}$ 

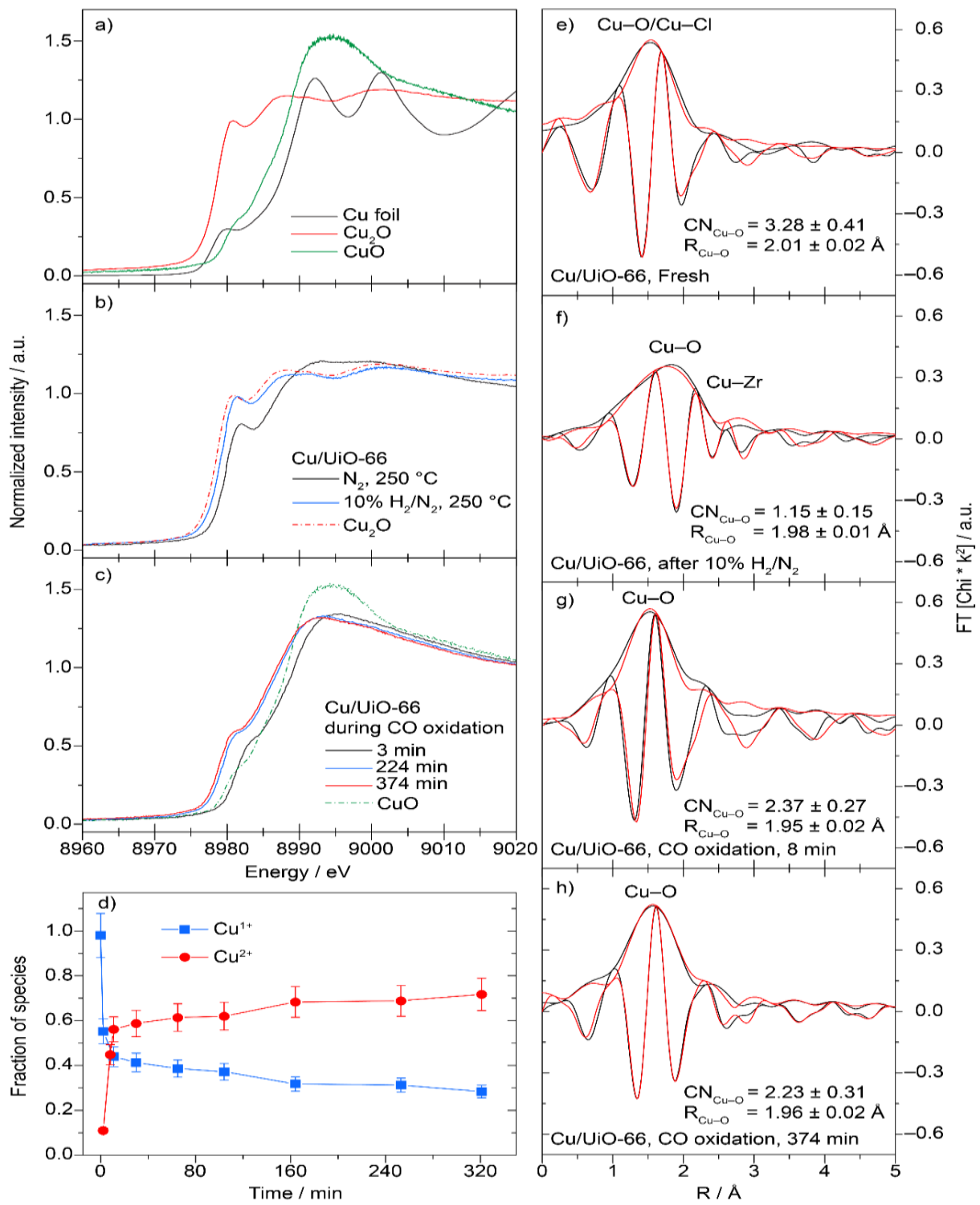

Figure 4. (a) Standard XANES spectra of a $\mathrm{Cu}$ foil, $\mathrm{Cu}_{2} \mathrm{O}$ and $\mathrm{CuO}$ recorded as references in $\mathrm{N}_{2}$ at room temperature. (b) Normalized XANES spectra of $\mathrm{Cu} / \mathrm{UiO}-66$ recorded after drying in $\mathrm{N}_{2}$ at $250{ }^{\circ} \mathrm{C}$ and after subsequent pretreatment in $10 \% \mathrm{H}_{2} / \mathrm{N}_{2}$. (c) Normalized XANES spectra of $\mathrm{Cu} / \mathrm{UiO}-66$ recorded during $\mathrm{CO}$ oxidation in an idealized $\mathrm{CO}$ oxidation gas mixture ( $1 \% \mathrm{CO}, 1 \%$ $\mathrm{O}_{2}, \mathrm{~N}_{2}$ balance $-30 \mathrm{NmL} \mathrm{min}^{-1}$ ) at selected times during the reaction. (d) Linear combination analysis (LCA) of the XANES spectra recorded during $\mathrm{CO}$ oxidation based on the reference spectra presented in a). (e, $\mathrm{f}, \mathrm{g}, \mathrm{h}$ ) Fourier transformed EXAFS spectra of the fresh $\mathrm{Cu} / \mathrm{UiO}-66$ catalyst in $\mathrm{N}_{2}$ at $25{ }^{\circ} \mathrm{C}(\mathrm{e})$, the catalyst in $\mathrm{N}_{2}$ after pretreatment in $10 \% \mathrm{H}_{2} / \mathrm{N}_{2}(\mathrm{f})$, during CO oxidation in idealized reaction gas mixture after $8 \mathrm{~min}(\mathrm{~g})$ and after 374 min on stream (h).

Eventually, a composition of $70 \% \mathrm{Cu}^{2+}$ and $30 \% \mathrm{Cu}^{1+}$ was reached after $375 \mathrm{~min}$ on stream. It should be noted that based on the data we cannot distinguish between a mixture of $70 \% \mathrm{Cu}^{2+}$ and $30 \% \mathrm{Cu}^{1+}$ and a situation with $100 \%$ of a $\mathrm{Cu}^{1.7^{+}}$species, where the lower charge (compared to $\left.\mathrm{Cu}^{2+}\right)$ is due to a covalent bond contribution. ${ }^{47}$ The fast change in the oxidation state of the $\mathrm{Cu}$ species during $\mathrm{CO}$ oxidation, from $1+$ to a higher oxidation state, agrees well with the fast decay in the intensity of the monocarbonyls adsorbed on $\mathrm{Cu}^{1+}$ sites $\left(2113 \mathrm{~cm}^{-1}\right)$ observed in the DRIFTS measurements. The higher wavenumber band developing after about 600 min of $\mathrm{CO}$ oxidation at $2132 \mathrm{~cm}^{-1}$ indicates a change in the nature of the $\mathrm{Cu}^{1+}$ formed during reaction, which might indicate a possible restructuring of the binding configuration of these species after longer reaction times. It should also be noted that since we essentially only see $\mathrm{Cu}^{1+}$-CO species in the IR spectra, these are the active sites for reaction. The absence of a visible band for $\mathrm{Cu}^{2+}$-CO moieties mainly reflects the much lower stability of these species and hence their lower abundance during reaction. Nevertheless, they may be involved in the reaction process, leaving the question for the active $\mathrm{Cu}$ species open. To test for thermal effects on the stability of the $\mathrm{Cu}^{2+}$ species under reaction conditions, we carried out similar XANES measurements during CO oxidation $(1 \%$ $\mathrm{CO}, 1 \% \mathrm{O}_{2}, \mathrm{~N}_{2}$ balance) at higher temperature, at $350^{\circ} \mathrm{C}$. 
Despite the high temperature, the LCA of the XANES spectra showed $75 \% \mathrm{CuO}$ and $25 \% \mathrm{Cu}_{2} \mathrm{O}$, only slightly above the values obtained at $250{ }^{\circ} \mathrm{C}$ (Supporting Information, Figure S16). Analysis of the extended X-ray absorption fine structure (EXAFS) spectra recorded during pretreatment and $\mathrm{CO}$ oxidation at $250{ }^{\circ} \mathrm{C}$ under similar conditions (Supporting Information, Figure S17) provided further information on the local environment of the $\mathrm{Cu}$ species during reaction. The Fourier transformed spectra of the fresh $\mathrm{Cu} / \mathrm{UiO}-66$ catalyst shown in Figure 4e reflects a distance of the main back-scattering shell of 2.01 $\pm 0.02 \AA$. This is assigned to a $\mathrm{Cu}-\mathrm{O}$ shell with an average coordination number of $3.3 \pm 0.4$. This indicates that $\mathrm{Cu}$ is bound to the $\mathrm{Zr}$ oxide clusters of $\mathrm{UiO}-66$ via the oxygen atoms ${ }^{43 ; 45}$ confirming our conclusions based on the DRIFTS and XANES data in Figures $1 \mathrm{~d}$ and $4 \mathrm{a}-\mathrm{d}$ described above. After the $\mathrm{H}_{2}$ pretreatment, the main backscattering of $\mathrm{Cu}-\mathrm{O}$ was observed at $1.98 \pm 0.02 \AA$ with a significant decrease of the coordination number to $1.15 \pm 0.4$ (Figure $3 \mathrm{f}$ ). This bond length is significantly longer than $\mathrm{Cu}-\mathrm{O}$ bonds in $\mathrm{Cu}_{2} \mathrm{O}(1.85 \AA)$, providing further proof of distinct differences in the coordination environments of the $\mathrm{Cu}$ atoms in $\mathrm{Cu} / \mathrm{UiO}-66$ and in $\mathrm{Cu}_{2} \mathrm{O}$ (Sup- porting Information, Figure S18) Interestingly, we also find a contribution, which would be equivalent to $2.88 \pm 0.02 \AA$ for $\mathrm{Cu}-\mathrm{Cu}$ backscattering, which, however, would be significantly larger than a typical $\mathrm{Cu}-\mathrm{Cu}$ shell in metallic $\mathrm{Cu}$, and shorter than in $\mathrm{Cu}$ oxides. As one possibility, this contribution may be related to $\mathrm{Cu}-\mathrm{Zr}$ backscattering. ${ }^{44 ; 45}$ After 8 min of $\mathrm{CO}$ oxidation, this shell disappeared (Figures $4 \mathrm{~g}-\mathrm{h}$ ), while the $\mathrm{Cu}-\mathrm{O}$ shell at $1.95 \pm 0.02$ $\AA$ A remained stable, but with higher coordination number of $2.37 \pm 0.27$.

Overall, comparison of the EXAFS data collected over a time of 375 min showed little change in both $\mathrm{Cu}-\mathrm{O}$ distance and coordination number of the $\mathrm{Cu}$ species during $\mathrm{CO}$ oxidation, except for the changes in the initial few minutes of the reaction (Supporting Information, Figure S19). Also these results point to a high stability of the coordination environment around the $\mathrm{Cu}$ atoms during the $\mathrm{CO}$ oxidation reaction (see Figure $4 \mathrm{~h}$ ). Altogether, these data underline the presence of individual $\mathrm{Cu}$ atoms in an atomically dispersed form, which are coordinated to two oxygen atoms each. This is distinctly different from the situation in $\mathrm{Cu}_{2} \mathrm{O}$ or $\mathrm{CuO}$ clusters / nanoparticles.
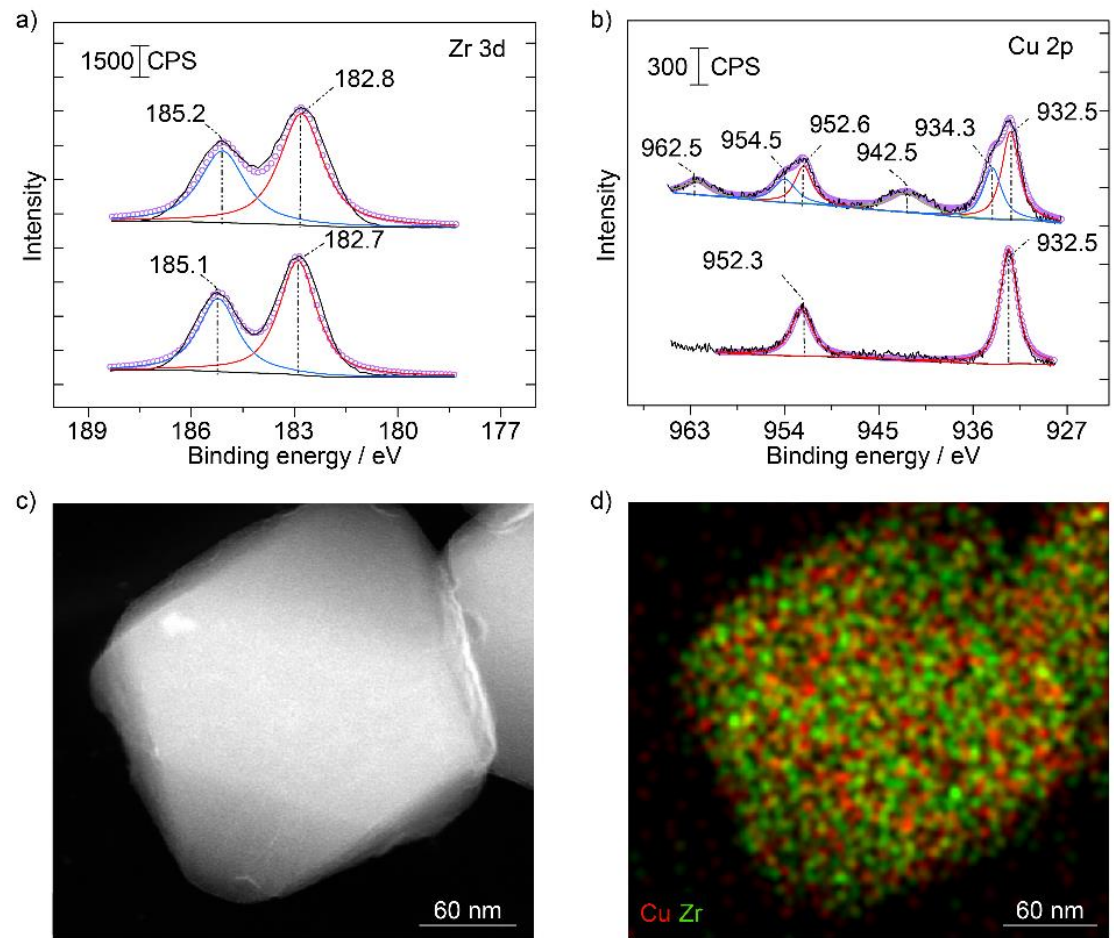

Figure 5. X-ray photoelectron spectroscopy spectra of $\mathrm{Cu} / \mathrm{UiO}-66 \mathrm{in}(\mathrm{a})$ the $\mathrm{Zr} 3 \mathrm{~d}$ region and (b) the $\mathrm{Cu} 2 \mathrm{p}$ region recorded after $\mathrm{H}_{2}$ treatment (bottom spectra) and after $\mathrm{CO}$ oxidation (see text, upper spectra). (c) High-angle annular dark-field scanning transmission electron microscopy (HAADF-STEM) image of the $\mathrm{Cu} / \mathrm{UiO}-66$ catalyst after $\mathrm{CO}$ oxidation during a temperature scan from 80 to $350^{\circ} \mathrm{C}$ and (d) the corresponding EDS map of the $\mathrm{Cu}$ and $\mathrm{Zr} \mathrm{K}$ lines. (e) High resolution HAADF-STEM image and (f) corresponding BF-STEM image recorded after $\mathrm{CO}$ oxidation during temperature scan between 80 and $350^{\circ} \mathrm{C}$.

To gain further information on the chemical state of the $\mathrm{Cu}$ species, we analyzed the fresh and spent $\mathrm{Cu} / \mathrm{UiO}-66$ catalysts by X-ray photoelectron spectroscopy (XPS). XPS spectra recorded in the $\mathrm{Zr}$ 3d region (see Figure 5a) showed insignificant changes of the $\mathrm{Zr}$ 3d core level for the spent catalyst $\left(3 \mathrm{~d}_{5 / 2}=182.7 \pm 0.1 \mathrm{eV}\right)$ compared to the fresh, non-treated sample $\left(3 \mathrm{~d}_{5 / 2}=182.8 \pm 0.1 \mathrm{eV}\right)$. These binding energies are characteristic of $\mathrm{Zr}^{4+}$ ions. ${ }^{15}$ For the 
$\mathrm{Cu} 2 \mathrm{p} 3 / 2$ main peak, the core $2 \mathrm{p}$ level energy shifts from 932.4 $\mathrm{eV}$ for the freshly reduced sample, after $\mathrm{H}_{2}$ treatment, to $932.7 \mathrm{eV}$ for the spent sample, after $\mathrm{CO}$ oxidation at temperatures from 80 to $350^{\circ} \mathrm{C}$ (300o min). Additionally, we observed new features at $942.2 \pm 0.1 \mathrm{eV}(2 \mathrm{p} 3 / 2)$ and 962.5 $\pm 0.1(2 \mathrm{pl} / 2) \mathrm{eV}$ after $\mathrm{CO}$ oxidation, which are identified as $\mathrm{Cu} 2 \mathrm{p}$ satellites, where the latter are characteristic of $\mathrm{Cu}^{2+}$ ions. ${ }^{48-50}$ These satellites have been assigned to a parallel excitation (shake-up) of a ligand electron into an empty $\mathrm{Cu}$ 3d state, which do not exist for $\mathrm{Cu}^{1+}$ and $\mathrm{Cu}^{\circ}$. The absence of the $\mathrm{Cu} 2 \mathrm{p}$ satellite clearly indicates that after $\mathrm{H}_{2}$ treatment there are only $\mathrm{Cu}^{1+}$ species present, in full agreement with XANES and EXAFS data. After CO oxidation, the presence of a pronounced $\mathrm{Cu} 2 \mathrm{p}$ satellite demonstrates the formation of $\mathrm{Cu}^{2+}$ ions. Since the intensity ratio between $\mathrm{Cu} 2 \mathrm{p}$ main peak and the satellite depends on the local environment of the $\mathrm{Cu}^{2+}$ ions, we cannot determine the $\mathrm{Cu}^{2+}: \mathrm{Cu}^{1+}$ ratio from these data. Similar to XANES analysis, a single $\mathrm{Cu}$ ion species with a formal charge of about 1.7+ would also be possible.

To further test for the presence of $\mathrm{Cu}$ clusters, we performed high-angle annular dark-field scanning transmission electron microscopy (HAADF-STEM) and EDS measure ments on the fresh (Supporting Information, Figure S20) and on the spent $\mathrm{Cu} / \mathrm{UiO}-66$ catalyst (see Figure $5 \mathrm{c}, \mathrm{d}$ ). For both samples, high resolution HAADF-STEM images do not show any features indicative of the formation of clusters of $\mathrm{Cu}, \mathrm{Cu}_{2} \mathrm{O}$ or $\mathrm{CuO}$, consistent with our findings from EXAFS. The EDS mapping of over 6o MOF crystals of the fresh and spent samples confirmed that the $\mathrm{Cu}$ species are uniformly distributed inside the MOF crystals (Figure ${ }_{5} \mathrm{~d}$ ), as would be expected for a MOF with single $\mathrm{Cu}$ atom. Furthermore, atomic resolution HAADF-STEM images (Supporting Information Figure S21), collected at the outermost parts of MOF microcrystals, show individual atoms / ions, in full agreement with the findings from XANES, EXAFS and XRD data.

Density Functional Theory Calculations. Finally, to obtain more detailed information about the structure of the catalyst, we performed density functional theory (DFT) calculations. Based on the experimental findings, we modeled the $\mathrm{Cu} / \mathrm{UiO}-66$ catalyst by anchoring $\mathrm{Cu}$ at ${ }^{-}$ $\mathrm{OH} / \mathrm{OH}_{2}$ ligands capping the defect sites of UiO-66 with a $\mathrm{Cl}^{-}$as a ligand (Figure 6a). The resulting optimized structure shows that in the fresh sample the $\mathrm{Cu}$ ions are threefold coordinated, binding to two oxygen atoms and one chlorine atom at bond distances of $\mathrm{Cu}-\mathrm{O}=1.89$ and 1.95 $\AA$, and $\mathrm{Cu}-\mathrm{Cl}=2.15 \AA$ (Figure $6 \mathrm{~b}$ ). To describe the structure after $\mathrm{H}_{2}$ pretreatment (Figure $6 \mathrm{c}$ ), where according to the XAS data the $\mathrm{Cu}$ species are reduced to $\mathrm{Cu}^{1+}$ and that these are atomically dispersed, we assumed that $\mathrm{Cu}$ is twofold coordinated, binding to ${ }^{-} \mathrm{OH} / \mathrm{OH}_{2}$ on the $\mathrm{Zr}$ oxide cluster,

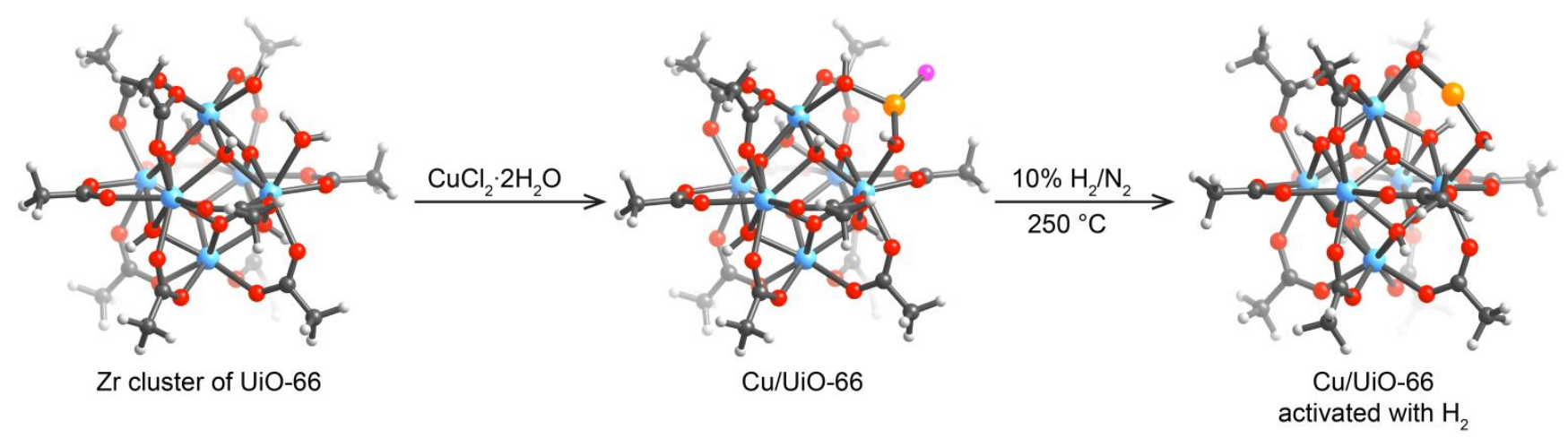

Figure 6. DFT calculated structures (a) of defective $\mathrm{UiO}-66$, (b) of a $\mathrm{Cu} / \mathrm{UiO}-66$ catalyst where $\mathrm{Cu}$ is coordinated to a $-\mathrm{OH}{ }_{2}$,$\mathrm{OH}^{-}$defect site of $\mathrm{UiO}-66$ (c), and (c) of a Cu/UiO-66 catalyst after activation with $\mathrm{H}_{2}$. Atom labeling: C: black; O: red; Cl: pink; $\mathrm{Cu}$ : orange; $\mathrm{Zr}$ : blue. $\mathrm{H}$ atoms are omitted for clarity.

and that the $\mathrm{Cl}$ ligand is removed. The optimized structure of $\mathrm{Cu} / \mathrm{UiO}-66$ shows similar $\mathrm{Cu}-\mathrm{O}$ bond distances of $1.86 \AA$, in good agreement with the EXAFS results. The decrease of the (formal) $\mathrm{Cu}-\mathrm{O}$ coordination number during the reductive pretreatment deduced from the EXAFS data points to some loss in the coordination shell, which was not considered in the calculations. Over all, the DFT calculations fully support our structural conclusions derived from the EXAFS measurements.

\section{CONCLUSIONS}

We have prepared a single-atom catalyst, where single $\mathrm{Cu}$ atoms are anchored to the oxygen atoms of $-\mathrm{OH} / \mathrm{OH}_{2}$ species capping the defect sites on the $\mathrm{Zr}$ oxide clusters of $\mathrm{UiO}-66$. Using the $\mathrm{CO}$ oxidation reaction and selective $\mathrm{CO}$ oxidation in $\mathrm{H}_{2}$-rich feed gases ( $\mathrm{H}_{2}$ purification) as test reactions, we found this catalyst to be highly active and stable even in $\mathrm{O}_{2}$-rich reaction atmospheres, under variable load conditions (startup/shutdown operation) and at temperatures up to $350^{\circ} \mathrm{C}$. In addition, it is highly selective (100 \%) for CO oxidation in the presence of up to $80 \% \mathrm{H}_{2}$ in the gas feed. Time-resolved operando spectroscopy indicates that the activity of the catalyst is asso- 
ciated with the atomically dispersed positively charged $\mathrm{Cu}$ species. We anticipate that the strategy reported here can be employed to synthesize single atom catalysts hosting other elements for a broad scope of catalytic transformations. Furthermore, the well-defined active site of this catalyst will enable detailed mechanistic investigations.

\section{ASSOCIATED CONTENT}

Supporting Information. Detailed description of synthesis and characterizations is supplied together with additional data including BET-Isotherms, NMR, TGA, PXRD, SEM, HRTEM, STEM-EDS, FTIR, XANES, EXAFS, and kinetic measurements (Figures S1-S18). This material is available free of charge via the Internet at http://pubs.acs.org."

\section{AUTHOR INFORMATION}

\section{Corresponding Author \\ * juergen.behm@uni-ulm.de ${ }^{*}$ yaghi@berkeley.edu,}

\section{Author Contributions}

\# These authors contributed equally

\section{ACKNOWLEDGMENT}

B.R. is supported by the Royal Thai Government Scholarship. The research performed in the O.M.Y. laboratory was supported by BASF SE (Ludwigshafen, Germany) and King Abdul-Aziz City for Science and Technology. Research work at the Molecular Foundry was supported by the Office of Science, Office of Basic Energy Sciences, of the DOE under Contract No. DE-ACo2-05CH11231. The Molecular Graphics and Computation Facility is funded by the NIH (S1oODo23532). The AVB-40o NMR spectrometer is partially supported by NSF Grant CHE-0130862. We thank the Institute of Engineering Materials and Biomaterials of the Silesian University of Technology for access to STEM imaging, and the Biological and Chemical Research Centre, University of Warsaw, for the possibility to perform the EDS analysis (co-funded by the European Union / European Regional Development Fund under the Operational Program Innovative Economy, 2007-2013). XAS measurements were carried out at P65 beamline, Petra-III (DESY, Germany) and XAFS beamline in Elettra Synchrotrone (Trieste, Italy). Work at the Advanced Light Source (ALS) is supported by Office of Basic Energy Sciences of the U.S. Department of Energy (DEACo2-05CH11231). Finally we would like to thank Dr. Thomas Diemant for XPS measurements (Institute of Surface Chemistry and Catalysis, Ulm University) and Drs. Simon J. Teat and Laura J. McCormick for synchrotron X-ray diffraction data acquisition support.

\section{REFERENCES}

(1) Qiao, B.; Wang, A.; Yang, X.; Allard, L. F.; Jiang, Z.; Cui, Y.; Liu, J.; Li, J.; Zhang, T., Single-Atom Catalysis of CO Oxidation Using $\mathrm{Pt}_{1} / \mathrm{FeO}_{\mathrm{x}}$, Nat. Chem. 2o11, 3, 634-641.

(2) Yang, M.; Li, S.; Wang, Y.; Herron, J. A.; Xu, Y.; Allard, L. F.; Lee, S.; Huang, J.; Mavrikakis, M.; Flytzani-Stephanopoulos, M., Catalytically Active Au-O (OH) ${ }_{x}$-Species Stabilized by Alkali Ions on Zeolites and Mesoporous Oxides, Science 2014, 346, 1498-1501.
(3) Malta, G.; Kondrat, S. A.; Freakley, S. J.; Davies, C. J.; Lu, L.; Dawson, S.; Thetford, A.; Gibson, E. K.; Morgan, D. J.; Jones, W., Wells, P.P.; Johnston, P.; Catlow, C. R.A; Kiely, C.J.; Hutchings, G. J., Identification of Single-Site Gold Catalysis in Acetylene Hydrochlorination, Science 2017, 355, 1399-1403.

(4) Zhang, H.; Liu, G.; Shi, L.; Ye, J., Single-Atom Catalysts: Emerging Multifunctional Materials in Heterogeneous Catalysis, Adv. Energy Mater. 2018, 8, 1701343.

(5) Campbell, C. T.; Parker, S. C.; Starr, D. E., The Effect of Size-Dependent Nanoparticle Energetics on Catalyst Sintering, Science 2002, 298, 811-814.

(6) Ouyang, R.; Liu, J. X.; Li, W. X., Atomistic Theory of Ostwald Ripening and Disintegration of Supported Metal Particles under Reaction Conditions, J. Am. Chem. Soc. 2013, 135, 1760-1771.

(7) Prieto, G.; Zecevic, J.; Friedrich, H.; de Jong, K. P.; de Jongh, P. E., Towards Stable Catalysts by Controlling Collective Properties of Supported Metal Nanoparticles, Nature Mater. 2013, 12, 34-39.

(8) Yuan, S.; Chen, Y.-P.; Qin, J.; Lu, W.; Wang, X.; Zhang, Q.; Bosch, M.; Liu, T.-F.; Lian, X.; Zhou, H. C., Cooperative Cluster Metalation and Ligand Migration in Zirconium Metal-Organic Frameworks, Angew. Chem. Int. Ed. 2015, 54, 14696-14700.

(9) Li, Z.; Peters, A. W.; Bernales, V.; Ortuno, M. A.; Schweitzer, N. M.; DeStefano, M. R.; Gallington, L. C.; PlateroPrats, A. E.; Chapman, K. W.; Cramer, C. J., Metal-Organic Framework Supported Cobalt Catalysts for the Oxidative Dehydrogenation of Propane at Low Temperature, ACS Cent. Sci. 2016, 3, 31-38.

(10) Kim, I. S.; Li, Z.; Zheng, J.; Platero-Prats, A. E.; Mavrandonakis, A.; Pellizzeri, S.; Ferrandon, M.; Vjunov, A.; Gallington, L. C.; Webber, T. E., Sinter-Resistant Platinum Catalyst Supported by Metal-Organic Framework, Angew. Chem. Int. Ed. 2018, 57, 909-913.

(11) Yaghi, O. M.; O'Keeffe, M.; Ockwig, N. W.; Chae, H. K.; Eddaoudi, M.; Kim, J., Reticular Synthesis and the Design of New Materials, Nature 2003, 423, 705-714.

(12) Li, Z.; Schweitzer, N. M.; League, A. B.; Bernales, V.; Peters, A. W.; Getsoian, A. B.; Wang, T. C.; Miller, J. T.; Vjunov, A.; Fulton, J. L., Sintering-Resistant Single-Site Nickel Catalyst Supported by Metal-Organic Framework, J. Am. Chem. Soc. 2016, 138, 1977-1982.

(13) Metzger, E. D.; Brozek, C. K.; Comito, R. J.; Dinca, M., Selective Dimerization of Ethylene to 1-Butene with a Porous Catalyst, ACS Cent. Sci. 2016, 2, 148-153.

(14) Manna, K.; Ji, P.; Lin, Z.; Greene, F. X.; Urban, A.; Thacker, N. C.; Lin, W., Chemoselective single-site Earth-Abundant Metal Catalysts at Metal-Organic Framework Nodes, Nat. Commun. 2016, 7, 12610.

(15) Rungtaweevoranit, B.; Baek, J.; Araujo, J. R.; Archanjo, B. S.; Choi, K. M.; Yaghi, O. M.; Somorjai, G. A., Copper Nanocrystals Encapsulated in Zr-based Metal-Organic Frameworks for Highly Selective $\mathrm{CO}_{2}$ Hydrogenation to Methanol, Nano Lett. 2o16, 16, 7645-7649.

(16) Zhao, M.; Yuan, K.; Wang, Y.; Li, G.; Guo, J.; Gu, L.; Hu, W.; hao, H.; ang, Z., Metal-Organic Frameworks as Selectivity Regulators for Hydrogenation Reactions, Nature 2016, 539, 7680.

(17) Platero-Prats, A. E.; Li, Z.; Gallington, L. C.; Peters, A. W.; Hupp, J. T.; Farha, O. K.; Chapman, K. W., Addressing the Characterisation Challenge to Understand Catalysis in MOFs: the Case of Nanoscale Cu Supported in NU-1000, Faraday Discuss. 2017, 201, 349-362.

(18) An, B.; Zhang, J.; Cheng, K.; i, P.; ang, C.; in, W., Confinement of Ultrasmall $\mathrm{Cu} / \mathrm{ZnO}_{\mathrm{x}}$ Nanoparticles in MetalOrganic Frameworks for Selective Methanol Synthesis from 
Catalytic Hydrogenation of $\mathrm{CO}_{2}$, J. Am. Chem. Soc. 2017, 139, 3834-3840.

(19) Gutterød, E. S.; Øien-Ødegaard, S.; Bossers, K.; Nieuwelink, A. E.; Manzoli, M.; Braglia, L.; Lazzarini, A.; Borfecchia, E.; Ahmadigoltapeh, S.; Bouchevreau, B.; LonstadBleken, B. T.; Henry, R.; Lamberti, C.; Bordiga, S.; Weckhuysen, B. M.; Lillerud, K. P.; Olsbye, U., $\mathrm{CO}_{2}$ Hydrogenation over PtContaining UiO-67 Zr-MOFs-The Base Case, Ind. Eng. Chem. Res. 2017, 56, 13206-13218.

(20). Lubitz, W.; Tumas, W., Hydrogen: An Overview, Chem. Rev. 2007, 107, 3900-3903.

(21) Weisz, P. B.: Intraparticle diffusion in catalytic systems, Chem. Engin. Progr. Symp. Ser. 1992, 55, 29-36.

(22) Kokoric, V.; Widmann, D.; Wittmann, M.; Behm, R. J.; Mizaikoff, B., Infrared Spectroscopy via Substrate-Integrated Hollow Waveguides: A Powerful Tool in Catalysis Research, Analyst 2016, 141, 5990-5995.

(23) Schubert, M. M.; Häring, T. P.; Bräth, G.; Gasteiger, H. A.; Behm, R. J., New DRIFTS Cell Design for the Simultaneous Acquisition of IR Spectra and Kinetic Data Using On-line Product Analysis, Appl. Spectrosc. 2001, 55, 1537-1543.

(24) Hamadeh, I. M.; King, D.; Griffiths, P. R., HeatableEvacuable Cell and Optical System for Diffuse Reflectance FT-IR Spectrometry of Adsorbed Species, J. Catal. 1984, 88, 264-272.

(25) Eckle, S.; Augustin, M.; Anfang, H.-G.; Behm, R. J., Influence of the Catalyst Loading on the Activity and the $\mathrm{CO}$ Selectivity in the Selective Methanation of $\mathrm{CO}$ in $\mathrm{CO}_{2}$ containing Feed Gases over Ru Supported Catalysts, Catal. Today 2012, 181, 40-51.

(26) Newville, M., IFEFFIT : interactive XAFS analysis and FEFF fitting, J. Synchrotron Rad. 2001, 8, 322-324.

(27) Koningsberger, D. C.; Mojet, B. L.; van Dorssen, G. E.; Ramaker, D. E., XAFS Spectroscopy; Fundamental Principles and Data Analysis, Top. Catal. 20oo, 10, 143-155.

(28) Bordiga, S.; Groppo, E.; Agostino, G.; van Bokhoven, J. A.; Lamberti, C., Reactivity of Surface Species in Heterogeneous Catalysts Probed by In Situ X.ray Absorption Techniques, Chem. Rev. 2015, 113, 1736-1850.

(29) Ankudinov, A. L.; Ravel, B.; Rehr, J. J.; Conradson, S. D., Real-Space Multiple-Scattering Calculation and Interpretation of X-ray-Absorption Near-Edge Structure, Phys. Rev. B 1998, 58 , 7565-7576.

(30) Trickett, C. A.; Gagnon, K. J.; Lee, S.; Gandara, F.; Bürgi, H. B.; Yaghi, O. M., Definitive Molecular Level Characterization of Defects in UiO-66 Crystals, Angew. Chem. Int. Ed. 2015, 54, 1116211167.

(31) Valenzano, L.; Civalleri, B.; Chavan, S.; Bordiga, S.; Nilsen, M. H.; Jakobsen, S.; Lillerud, K. P.; Lamberti, C., Disclosing the Complex Structure of UiO-66 Metal Organic Framework: a Synergic Combination of Experiment and Theory, Chem. Mater. 2011, 23, 1700-1718.

(32) Ling, S.; Slater, B., Dynamic Acidity in Defective UiO-66, Chem. Sci. 2016, 7, 4706-4712.

(33) Yang, D.; Ortuno, M. A.; Bernales, V.; Cramer, CJ.; Gagliardi, L.; Gates, B. C., Structure and Dynamics of $\mathrm{Zr}_{6} \mathrm{O}_{8}$ Metal-Organic Framework Node Surfaces Probed with Ethanol Dehydration as a Catalytic Test Reaction, J. Am. Chem. Soc. 2018, 140, 3751-3759.

(34) Farrauto, R.; Heck, R. M., Catalytic Converters: State of the Art and Perspectives, Catal. Today 1999, 51, 351-360.
(35) Morales, F.; Viniegra, M.; Arroyo, R.; Cordoba, G.; Zepeda, T. A., $\mathrm{CO}$ oxidation Over $\mathrm{CuO} / \mathrm{ZrO}_{2}$ Catalysts: Effect of Loading and Incorporation Procedure of CuO, Mater. Res. Inno. 2010, 14, 183-188.

(36) Li, Y.; Cai, Y.; Xing, X.; Chen, N.; Deng, D.; Wang, Y., Catalytic Activity for $\mathrm{CO}$ Oxidation of $\mathrm{Cu}-\mathrm{CeO}_{2}$ Composite Nanoparticles Synthesized by a Hydrothermal Method, Anal. Methods 2015, 7, 3238-3245.

(37) Bera, P.; Patil, K. C.; Jayaram, V.; Subbanna, G. N.; Hegde, M. S., Ionic Dispersion of Pt and $\mathrm{Pd}$ on $\mathrm{CeO}_{2}$ by Combustion Method: Effect of Metal-Ceria Interaction on Catalytic Activities for NO Reduction and CO and Hydrocarbon Oxidation, J. Catal. 2000, 196, 293-301.

(38) Kahlich, M. J.; Gasteiger, H. A.; Behm, R. J., Kinetics of the Selective CO Oxidation in $\mathrm{H}_{2}$-rich Gas on $\mathrm{Pt} / \mathrm{Al}_{2} \mathrm{O}_{3}$, Journal of Catalysis 1997, 171, 93-105.

(39) Kahlich, M. J.; Gasteiger, H. A.; Behm, R. J., Kinetics of the Selective Low-Temperature Oxidation of $\mathrm{CO}$ in $\mathrm{H}_{2}$-rich Gas over $\mathrm{Au} / \mathrm{a}-\mathrm{Fe}_{2} \mathrm{O}_{3}$, J. Catal. 1999, 182, 430-440.

(40) Hadjiivanov, K.; Knözinger, H., FTIR study of CO and NO Adsorption and Coadsorption on a $\mathrm{Cu} / \mathrm{SiO}_{2}$ catalyst: Probing the Oxidation State of Copper, Phys. Chem. Chem. Phys. 2oo1, 3, 1132-1137.

(41) Giordanino, F.; Vennestrom, P. N. R.; Lundegaard, L. F.; Stappen, F. N.; Mossin, S.; Beato, P.; Bordiga, S.; Lamberti, C., Characterization of $\mathrm{Cu}$-Exchanged SSZ-13: a Comparative FTIR, UV-Vis, and EPR study with Cu-ZSM- 5 and $\mathrm{Cu}-\mathrm{b}$ with Similar $\mathrm{Si} / \mathrm{Al}$ and $\mathrm{Cu} / \mathrm{Al}$ ratios, Dalton Trans. 2013, 42, 12741-12761.

(42) Hadjiivanov, K.; Knözinger, H., FTIR Study of LowTemperature CO Adsorption on $\mathrm{Cu}-\mathrm{ZSM}-5$ : Evidence of the Formation of $\mathrm{Cu}^{2+}(\mathrm{CO})_{2}$ Species, J. Catal. 20oo, 191, 480-485.

(43) Okamoto, Y.; kubota, T.; Gotoh, H.; Ohto, Y.; Aritani, H.; Tanaka, T.; Yoshida, S., XAFS Study of Zirconia-Supported Copper Catalysts for the NO-CO Reaction: Deactivation, Rejuvenation and Stabilization of $\mathrm{Cu}$ Species, J. Chem. Soc. Faraday Trans 1998, 94, 3743-3752.

(44) Caballero, A.; Morales, J. J.; Cordon, A. M.; Holgado, J. P.; Espinos, J. P.; Gonzalez-Elipe, A. R., An In Situ XAS study of $\mathrm{Cu} / \mathrm{ZrO}_{2}$ Catalysts Under de- $\mathrm{NO}_{\mathrm{x}}$ Reaction Conditions, J. Catal. 2005, 235, 295-301.

(45) Muddada, N. B.; Olsbye, U.; Leofanti, G.; Gianolio, D.; Bonino, F.; Bordiga, S.; Fuglerud, T.; Vidotto, S.; Marsella, A.; Lamberti, C., Quantification of Copper Phases, Their Reducibility and Dispersion in Doped- $\mathrm{CuCl}_{2} / \mathrm{Al}_{2} \mathrm{O}_{3}$ Catalysts for Ethylene Oxychlorination, Dalton Trans. 2010, 39, 8437-8449.

(46) Su, Y.; Brown, H. M.; Li, G.; Zhou, X. D.; Amonette, J. E.; Fulton, J. L.; Camaioni, D. M.; Zhang, Z. C., Accelerated Cellulose Depolymerization Catalyzed by Paired Metal Chlorides in Ionic Liquid Solvent, Appl. Catal. A 2011, 391, 436-442.

(47) Chakhalian, J.; Freeland, J. W.; Habermeier, H. U.; Cristiani, G.; Khaliullin, G.; Van Veenendaal, M.; Keimer, B., Orbital Reconstruction and Covalent Bonding at an Oxide Interface, Science 2007, 318, 1114-1117.

(48) Larsson, S., Theory of Satellite Excitations in Inner Shell X-ray Photoelectron Spectra of Nickel and Copper Compounds, Chem. Phys. Lett. 1975, 32, 401-406.

(49) Larsson, S., Shake-up and Multiplet Structure of ESCA Satellites of Cu Compounds, Chem. Phys. Lett. 1976, 40, 362-366.

(50) Ghijsen, J.; Tjeng, L. H.; Van Elp, J.; Eskes, H.; Westerink, J.; Sawatzky, G. A.; Czyzyk, M. T., Electronic Structure of $\mathrm{Cu}_{2} \mathrm{O}$ and $\mathrm{CuO}$, Phys. Rev. B 1988, 38, 11322. 


\section{Table of Contents Artwork}

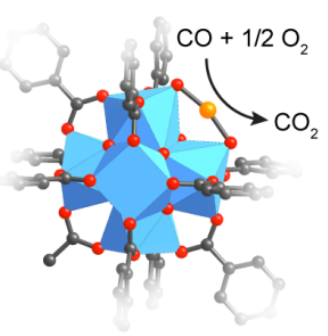

Single-atom Cu catalyst in MOF

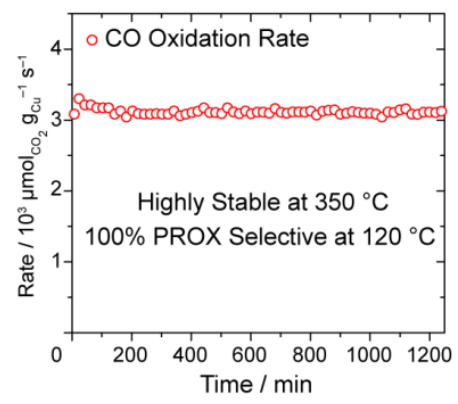

